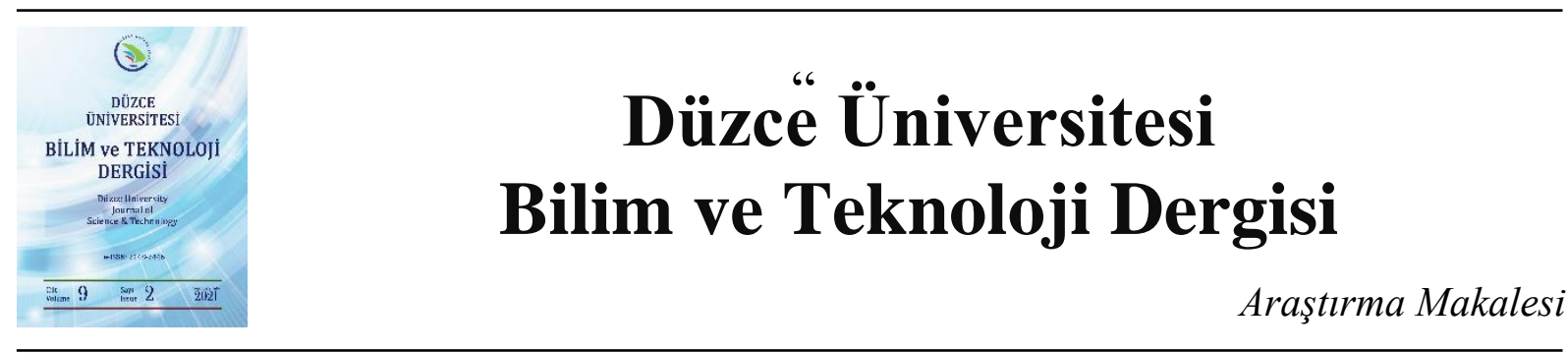

\section{Katlı Yığma Binanın Deprem Performansının Belirlenmesi ve Güçlendirme Önerileri}

\author{
Ömer CAN ${ }^{\mathrm{a} *}$ \\ a İşaat Mühendisliği Bölümü, Mühendislik Fakültesi, Bayburt Üniversitesi, Bayburt, TÜRKİYE \\ * Sorumlu yazarın e-posta adresi: ocan@bayburt.edu.tr
}

DOI:10.29130dubited.842317

ÖZET

\begin{abstract}
Ülkemiz de yığma yapılar tarihi özelliğe sahip yapılardır. Genellikle ülkemizin kırsal bölgelerinde yerel malzeme kullanılarak yapılan yığma yapılara rastlamak oldukça mümkündür. Yığma yapılar mühendislik hizmetine ihtiyaç duyulmadan çok çeşitli özellikteki malzeme ve iş̧̧ilik hizmetine sahiptir. Bunun sonucu olarak düşey yükler ve deprem yükleri altındaki performansının belirlenmesi günümüzdeki betonarme yapıların performans analizlerine göre güçtür. Bu çalışmada; Bayburt ili merkezinde bulunan, 1997-1998 yılları arasında inşa edilen, Zemin +4 katlı toplam 5 katlı kâgir yapının yapım tekniği, malzeme özellikleri ve konum özellikleri hakkında bilgiler derlenmiştir. Yapıda gözlemlenen mevcut problemler belirlenmiştir. StatiCAD-Yığma programı kullanılarak 2018 Bina Deprem Yönetmeliği dikkate alınarak yapının performans analizi yapılmıştır. Analiz sonucunda binayı dıştan tek taraflı donatılı sıva ile içten kısmi olarak bazı duvarları çift taraflı donatılı sıva ile güçlendirme yöntemi önerilmiştir. Binanın güçlendirme öncesi yapılan analizde 48 duvar basınç ve kayma gerilmesi açısından yetersiz ve göçme durumunda iken, güçlendirme sonrası yapılan performans analizinde tüm duvarların emniyet gerilmelerini sağladığı ve hemen kullanım durumunda olduğu sonucuna varılmıştır.
\end{abstract}

Anahtar kelimeler: Yı̆̆ma Yapı, Performans Analizi, StatiCAD-Yığma

\section{Determination of Earthquake Performance of 5-Storey Masonry Building and Suggestions for Strengthening}

\begin{abstract}
$\underline{\text { ABSTRACT }}$
Masonry structures in our country are structures with historical features. Generally, it is quite possible to come across masonry structures made using local materials in rural areas of our country. Masonry structures have a wide variety of material and workmanship services without the need for engineering services. As a result, determining the performance under vertical loads and earthquake loads is difficult according to the performance analysis of today's reinforced concrete structures. In this study; Information about the construction technique, material properties and location features of the 5 -storey masonry building with ground +4 floors, located in the city centre of Bayburt, built between 1997-1998. The existing problems observed in the building have been identified. By using the StatiCAD-Masonry program, the performance analysis of the building was made taking into account the 2018 Building Earthquake Code. As a result of the analysis, a method of reinforcing the building with plaster reinforced on one side from the outside and partially on the inside with double-sided reinforced plaster is proposed. While 48 walls were inadequate in terms of pressure and shear stress in the analysis made before the reinforcement, it was concluded in the performance analysis made after the reinforcement that all walls provided the safety stresses and were in immediate use.
\end{abstract}

Keywords: Masonry Structure, Performance Analysis, StatiCAD-Yı̆̆ma 


\section{GIRIS}

Türkiye'de geçmişten günümüze tarihe geçmiş birçok deprem gerçekleşmiştir. Bilindiği üzere yaşadığımız depremler can ve mal kaybına sebep olmuştur. İstenmeyen can ve mal kaybı için yapıların depreme karşı sağlam olması zorunludur. Bunun üzerine yapılan birçok çalışma ortaya koyulmuştur [1], [2]. Günümüze kadar varlığını sürdüren tarihi önem taşıyan yığma yapıların ülkemizde sayısı oldukça fazladır. Kırsal bölgelerde çoğunlukta olmak üzere ülkemizin büyük çoğunluğunu yığma yapılar oluşturmaktadır [3]. Önceliklerimizden biri de bu yapıları ileri çağlara taşımaktır. Tarihi önem taşıyan yı̆̆ma yapıların günümüze kadar gelmesi yapısal özelliklerinin ve depreme karşı performansının daha anlaşılır olması gerektiğini bizlere göstermektedir [2], [4], [5]. Yığma yapıların güvenliklerinin belirlenmesi oldukça önemlidir. Koruma yöntemlerinin belirlenmesi oldukça titizlik içeren bir çalışma gerektirir. Yapının gerçeğe uygun modellenmesi daha garantici sonuçlar verecektir [6]. Yığma yapıların yapısal davranış ve deprem performansı hakkında bilgi edinebilmek için her bir yapının ayr1 ayrı incelenmesi gerekmektedir. Aynı zamanda yap1 performansını etkileyecek zemin oturmaları yapı malzeme dayanım düşüşleri, doğal afetler, olumsuz çevre koşulları vb. durumlar ihmal edilmemelidir. Yıllardır yapılan çalışmalar sonucu elde edilen bilgiler dâhilinde betonarme ve çelik yapıların yatay ve düşey yükler altında performanslarını ifade etmek belli bir doğruluk payıyla mümkündür. Yığma yapıların performansını ifade etmek ise daha çok belirsizlik içermektedir. Yığma yapıların değişken malzemeleri, işçilikleri, düzensizlik ve süreksizliklerinden dolayı yapısal performansını ifade etmekte zorluk çekilebilmektedir [7]-[11]. Yığma yapıların mevcut durumu ve ilerdeki zaman dilimlerinde muhtemel hasarlara karşı yapısal davranışlarının belirlenmesi için; Yapı hakkında bilgi edinilmelidir. Yapının rölöve çizimleri çıkarılmalıdır. Yapılan modelleme üzerinde statik ve dinamik analizler yapılmalıdır. Yapının maruz kaldığı mevcut yükler altında davranışları bilinmelidir. Hasar görmüş yapı elemanları ve hasar görebilecek yapı elemanlarını tespit etmek gereklidir. Yapının analizinden sonra analiz sonuçları değerlendirilmelidir. Yapının güçlendirmeye ihtiyaç duyup duymadığına karar verilmelidir. Karar sonucu güçlendirme yöntemine karar verilmeli, uygulama sonucunda analiz değerlerine göre uygunluğu değerlendirilmelidir [12]-[14]. Yakın zamanda yığma yapılar üzerinde yapılan çalışmalarda; yapıya güçlendirme perdeleri ekleyerek ETABS programı yardımıyla Mod Birleştirme yöntemini kullanarak, düzlem dışı hasarlara karşı, yapıda oluşan gerilmeleri katı elemanlar kullanıp modelleyerek sonuçları analitik ve lineer yöntemle, performans seviyelerini belirlemiş ve çeşitli güçlendirme yöntemleri önermişlerdir [15]-[17].

$\mathrm{Bu}$ çalışmada, Bayburt ilinde bulunan, çok katlı yığma yapıları temsilen Zemin +4 katlı kargir bina seçilmiştir. Bina 1998 yılında yapılmış çok katlı yığma yapılara örnek teşkil etmektedir. Binanın dayanımının belirlenmesi ve gerekirse onarım/güçlendirme önermek için StatiCAD-Yığma analiz programı kullanılarak performans analizi yapılması hedeflenmiş, elde edilen sonuçlar değerlendirilerek güçlendirme önerilerde bulunulmuştur.

\section{MALZEME VE YÖNTEM}

\section{A. 5 KATLI YIĞMA BINANIN ÖZELLÍKLERİ}

Yığma yapılar kullanım amacına ve yere göre farklı malzemeler kullanılarak yapılmaktadır. Genelde taşıyıcı olan duvarlarda; doğal taş, tuğla, kerpiç ve ahşap malzemeler kullanılmaktadır. Bu çalışmada, Bayburt ili, Merkez ilçesi, Tuzcuzade Mahallesi, Gürkan Ögüt Sokakta bulunan 512 ada, 45 parselde bulunan 5 katlı kargir yapı incelenmiştir. Bina 1997-1998 yılları arasında inşa edilmiştir. Zemin ve dört normal kattan oluşan binanın iç ve dış duvarları ateş tuğlası olarak bilinen 19x9x5 cm boyutlarında harman tuğla kullanılarak inşa edilmiştir. Duvar kalınlıkları $20 \mathrm{~cm}$ dir. Duvar örgü tipi tuğla derzleri birbiri üzerine kaydırılarak şaşırtma örgü tipi kullanılarak yapılmıştır. Dış ve iç cepheler normal çimentolu sıva harcı ile sıvanmıştır. Yığma binanın ön ve arka cephe görünümü Şekil 1'de verilmiştir. 

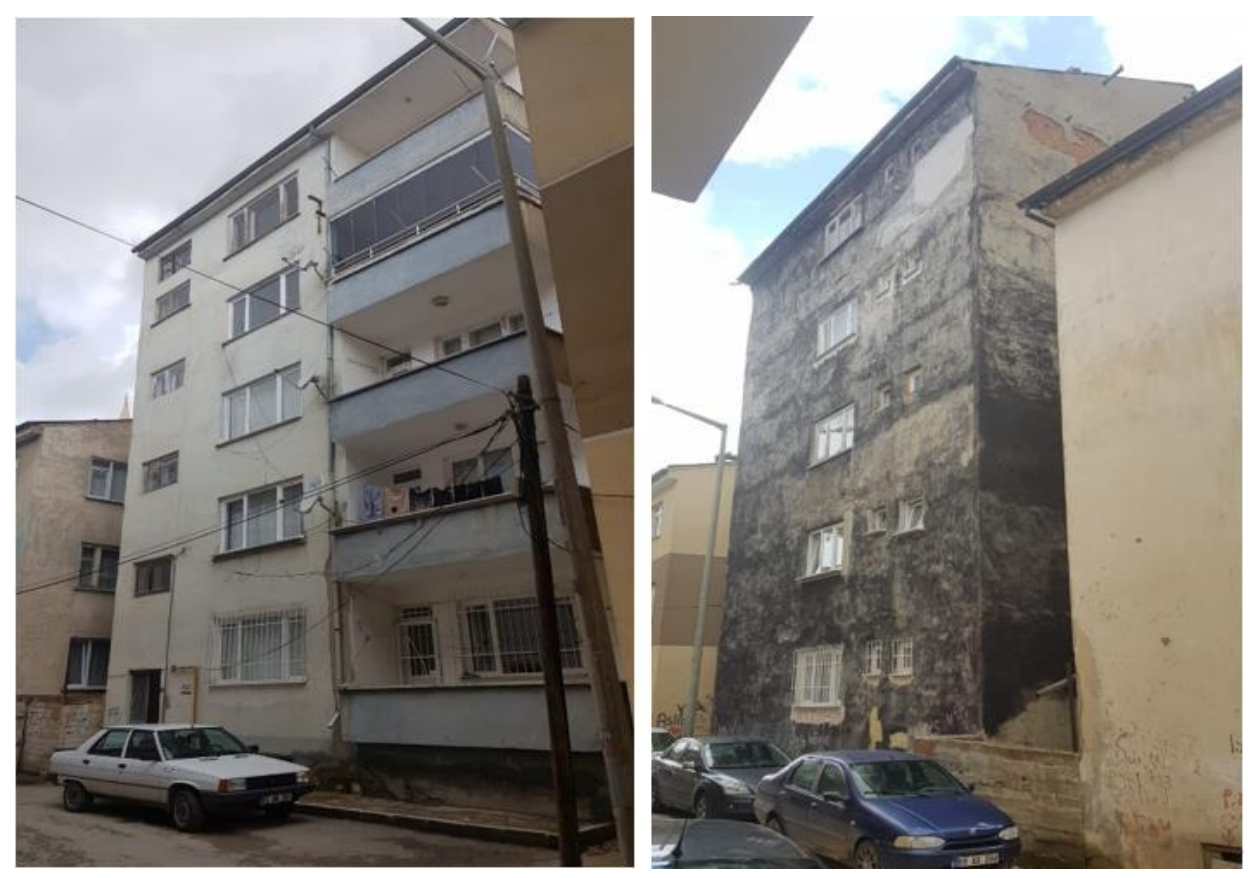

Şekil 1. Ön ve Arka cephe Görünümü

\section{B. MALZEME ve ÖZELLIKKLERİ}

Yapılan çalışmalarda ateş tuğlasının basınç dayanımının iyi olduğu, çekme dayanımının düşük olduğu görülmektedir. Yığma yapıda kullanılan malzemelerin özelliklerini deneysel olarak belirlenemediği durumlarda, kullanılan malzemelerin özellikleri literatürdeki benzer çalışmalardan alınabilmekte veya 2018 Bina Deprem Yönetmeliğindeki benzer malzemelerin dayanım değerleri kullanılabilmektedir [17]-[19]. Yığma yapılarda kullanılan $185 \times 85 \times 55 \mathrm{~mm}$ boyutlarındaki harman tuğlasının, Basınç dayanımı $5 \mathrm{MPa}$, Kayma Dayanımı 2.5 MPa ve Elastisite Modülü $3750 \mathrm{MPa}$ olarak alınmıştır [20]. Şekil 2'de incelenen yapıda kullanılan tuğlanın örgü tipine ait temsili görünüm verilmiştir. Güçlendirme için kullanılan donatı ve sıva özellikleri, güçlendirme bölümünde verilmiştir.

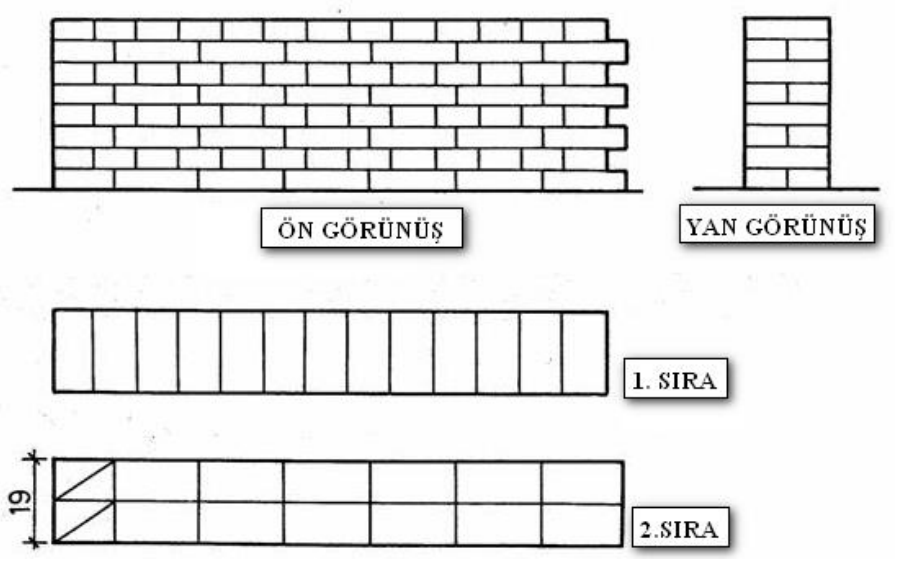

Şekil 2. Harman Tuğla ve Şaşırtma örgülü duvar temsili görünümü

\section{YÖNTEM}

Günümüzde bilgisayar yazılımları ile yapıların modellenmesi kolaylıkla yapılabilmektedir. Betonarme yapılara göre yığma yapılardaki analizlerde kullanılan eleman ve kabuller farklılık göstermektedir. 
Betonarme yapılarda sonlu elemanlar yöntemi kullanılırken, yığma yapılarda taşıyıcı duvar elemanlarını sonlu elaman yöntemi ile modellemek zorlaştırmaktadır. Yığma yapıların analizinde, üç farklı modelleme tekniği kullanılmaktadır. Bunlar; detaylı mikro modelleme, basitleştirilmiş mikro modelleme ve makro modellemedir.

Detaylı mikro modellemede, yığma duvarı meydana getiren yığma birimin ve harcın ayrı ayrı mekanik özellikleri yani Elastisite Modülleri, Poisson Oranları ve elastik olmayan diğer özellikleri dikkate alınmaktadır. Basitleştirilmiş mikro modelleme tekniği de bu tekniklerden birisidir. Basitleştirilmiş Mikro Modelleme Tekniği kullanılarak yapılan modellemelerde, muhtemel göçme mekanizmalarının tümünün dikkate alınmaması önemli sorunlardan birisidir. Makro modellemede, yığma birim ve harcın özellikleri çeşitli homojenleştirme işlemlerine tabi tutulmak suretiyle yığma duvar kompozit bir malzeme olarak düşünülmektedir. $\mathrm{Bu}$ modelin mekanik özellikleri homojenleştirme işlemleri sonucunda elde edilmektedir [14], [21].

$\mathrm{Bu}$ çalışmada analizini yapılan binada, deneysel çalışma yapılarak malzeme dayanımları elde edilmediği için tüm yapı bileşenlerinin kompozit özellik gösterdiği varsayımı üzerinden makro modelleme tekniği kullanılmıştır. StatiCAD-Yığma programı, makro modelleme yaparak, yığma yapıların deprem yönetmeliği esaslarına göre ortogonal (yüke maruz kalan elemanlar birbirine dik) statik analizinin ve proje çiziminin yapılmasını sağlayan bir programdır. Döşemeden duvarlara gelen yükleri kum tümseği analojisi yöntemi ile hesaplamaktadır. StatiCAD-Yığma Programı depreme dayanıklı yapı tasarımı için geliştirilen, yığma yapılar için geliştirilen statik analiz programdır. $\mathrm{Bu}$ program ile yeni yapıların projelendirilmesi yapıldığı gibi mevcut yapıların deprem performans analizleri güçlendirmesi yapılabilmektedir. 2018 Bina Deprem Yönetmeliği'ne uygun olarak mevcut binaların performans analizleri yapılabilmektedir.

Analizi yapılan binanın projeleri bulunmadığından rölöve projesi hazırlanmıştır (Şekil 3). Temeli taşıyıcı duvarların altında devam eden betonarme sürekli bir temel olarak seçilmiştir. Binanın yapım yılına göre 1998 yönetmeliğine tabi olduğu için beton kalitesi en az C16 MPa olarak alınmıştır. Binanın giriş cephesi $11.26 \mathrm{~m}$, yan cephesi 11.22 m'dir. Yapı ön cepheden bakıldığında kare bir geometriye sahiptir. 5 katlı kargir binanın boyutlandırılmasından önce yapıya ait zemin değerleri, bitişik parsellerde inşa edilmiş son dönem yapılarının zemin etüt raporları incelenerek belirlenmiştir. $\mathrm{Bu}$ alınan zemin etüt raporlarında verilen değerler birbirine yakın bulunmuştur. Bunlardan yapıya en yakında bulunan binanın zemin etüt raporu referans alınmıştır. Bu değerler Tablo 1'de verilmiştir. Yapının boyutlandırılmasında gerçek malzemeye en uygun malzeme ile boyutlandırma yapılmaya çalışılmıştır. Zemin ve dört normal kattan oluşan yapının döşemesi betonarmedir. Zemin kat dâhil tüm katlarda planlar aynıdır. Düşey ve yataydaki hatıllar gerçek boyutlarına uygun olarak modellenmiştir. Betonarme döşeme için beton sınıfı $16 \mathrm{MPa}$ alınırken donatı sınıfı S 220 alınmıştır. Analiz yaparken kullanılan yük kombinasyonları Tablo 2'de, taşıyıcı sistem katsayıları ise Tablo 3'te verilmiştir. Toplanan bu bilgiler 1şığında 2018 Bina Deprem Yönetmeliğine göre 5 katlı kargir yapının modellenmesi yapılmıştır. Binanın oluşturulan modeline ait görünüşler Şekil 4’te verilmiştir.

Tablo 1. 5 Katlı Kâgir Yapının Zemin Etüt Değerleri

\begin{tabular}{lcc}
\hline Zemin Parametreleri & Değerler \\
\hline Yerel Zemin Sınıfi & ZC \\
\hline Deprem Yer Hareket Düzeyi (DD) & 2 & \\
\hline Bina Koordinatları (Enlem/boylam) & $40.256306^{\circ}$ & $40.223983^{\circ}$ \\
\hline Harita spektral ivme katsayıları & $S_{\mathrm{S}}=0.546$ & $S_{1}=0.161$ \\
\hline Yerel Zemin Etki Katsayıları & $F_{\mathrm{S}}=1.28$ & $F_{1}=1.5$ \\
\hline Tasarım Spekral İvme katsayıları & $S_{\mathrm{DS}}=0.7$ & $S_{\mathrm{DI}}=0.24$ \\
\hline Yatay Elastik Tasarım Spektrumu & $\mathrm{TA}=0.07(\mathrm{~s})$ & $\mathrm{TB}=0.35(\mathrm{~s})$ \\
\hline
\end{tabular}




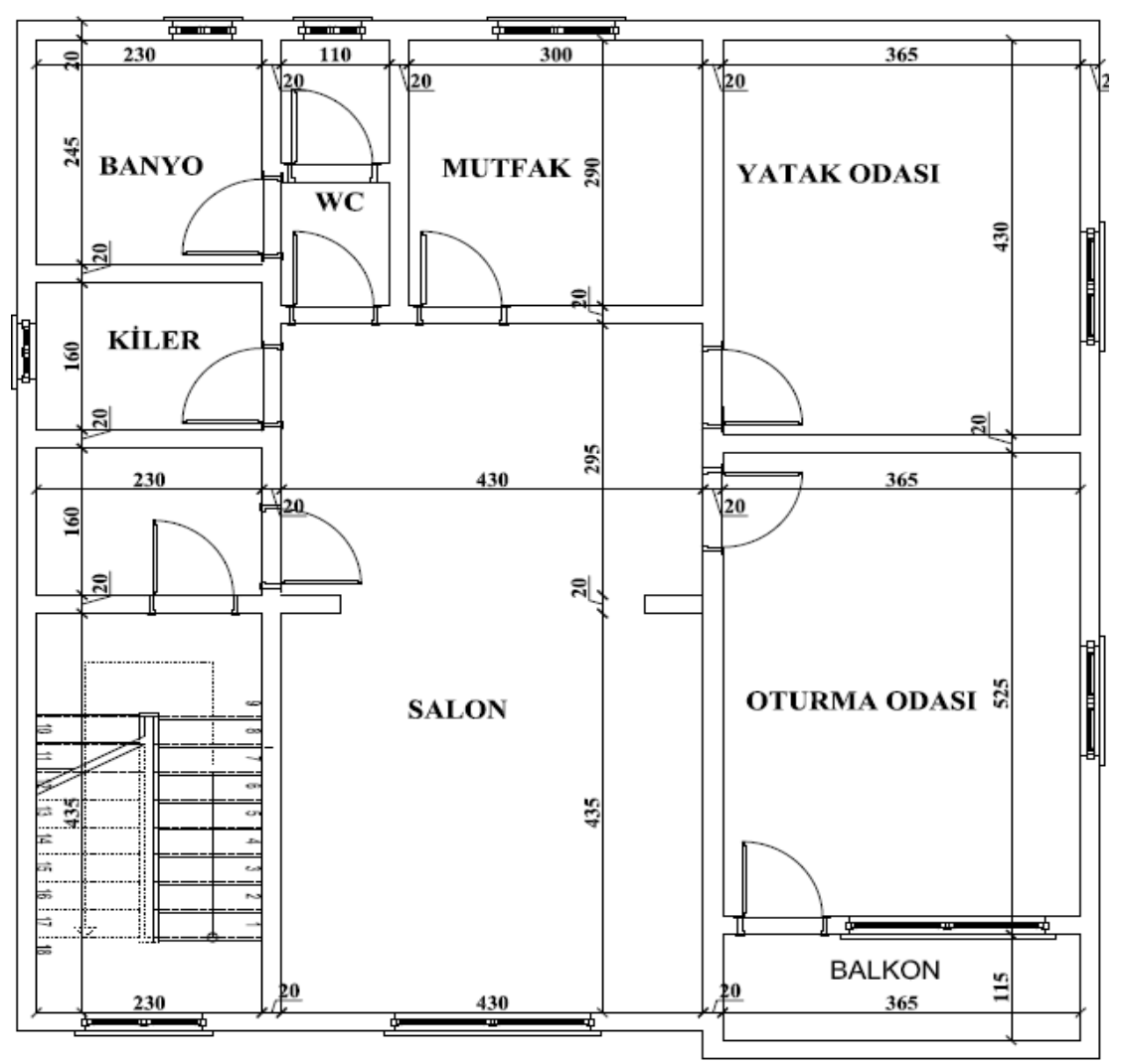

Şekil 3. 5 Katlı Kargır Yapıya Ait Rölöve (Zemin + Normal Kat)

Tablo 2. Gerekli Yük Kombinasyonlarl (TS 500,2000)[22]

\begin{tabular}{llll}
\hline Yük Kombinasyonları & G & Q & E \\
\hline Basınç Gerilmesi için Yük Katsayıları & 1.0 & 1.0 & - \\
\hline Betonarme Döşeme için Yük Katsayıları & 1.4 & 1.6 & - \\
\hline Kayma Gerilmesi Hesabı için Yük Katsayıları & 1.0 & HYKK & 1.0 \\
\hline
\end{tabular}

G: Ölü Yük; Q: Hareketli Yük; E: Deprem Yükü; HYKK: Hareketli Yük Katılım Katsayısı

Tablo 3. Taşıyıcı Sistem Katsayıları (TDY-2018)

\begin{tabular}{cc}
\hline Taşıyıcı sistem Parametreleri & Değerler \\
\hline BKS & 3 \\
$\mathrm{I}$ & 1 \\
\hline $\mathrm{A}_{0}$ & 0.4 \\
$\mathrm{R}$ & 4 \\
$\mathrm{ST}$ & 2.5 \\
\hline
\end{tabular}

BKS: Bina Kullanım Sınıfi; I: Bina Önem Katsayısı; A A : Etkin Yer İvmesi Katsayısı R: Taşıyıcı Sistem Davranış Katsayısı; ST: Spektrum Katsayısı 
StatiCAD-Yığma programına tüm veriler ve rölöve çizimleri girildikten sonra katlara etkiyen deprem kuvvetleri, katlarda oluşan kesme kuvvetleri tespit edilmiştir. Ayrıca her kat için kütle ve kayma merkezi miktarı bulunmuştur. Analiz sonucunda binadaki taşıyıcı her bir duvara ait kayma gerilmesi ve basınç gerilmesi bulunmuş, TDY-2018'e göre yetersiz olan duvarlar tespit edilmiştir.
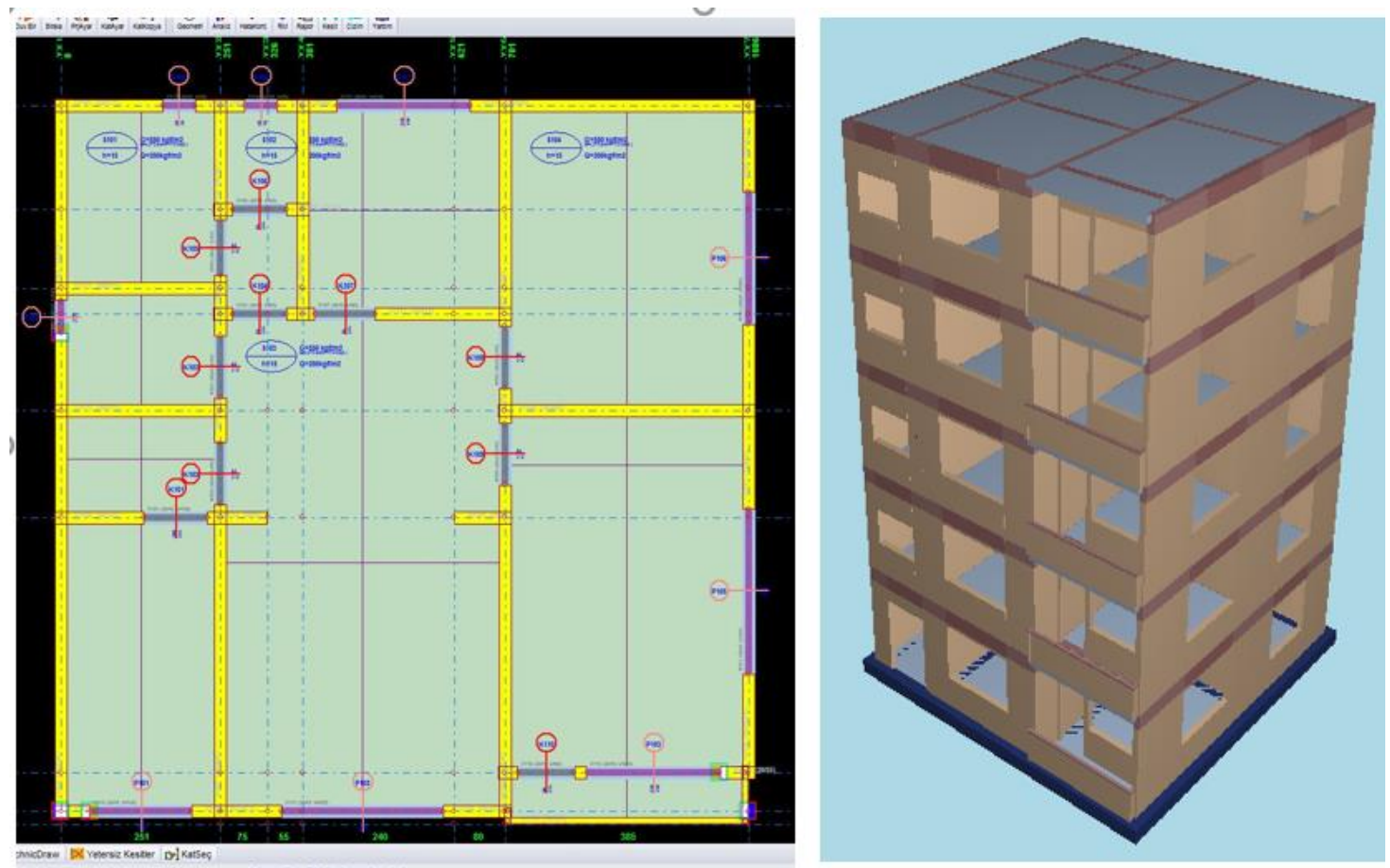

Şekil 4. 5 Katlı Yığma Binanın Kat Planı Rölövesi ve Üç Boyutlu Modeli

\section{ANALIZ VE BULGULAR}

\section{A. 5 KATLI KARGÍR YAPININ PERFORMANS ANALIZİ}

5 Katlı Kargir Yapının performans analizi yapılmadan önce analiz için 2018 Deprem Yönetmeliği seçilmiş, analiz öncesi yapının rölövesi çıkarılmış ve kapsamlı bilgi düzeyi olarak programa girilmiştir. 50 yılda aşılma olasılığ $1 \% 10$ olan depremler için, gerekli kabuller yapılarak yaptığımız hesaplar sonucunda, kayma gerilmesini sağlamayan yapı elemanlarının, toplam kesme kuvvetlerine oranları sırası ile; Zemin kat, X-X yönünde $\% 93.9$, Zemin kat $Y-Y$ yönünde, \%19.5, Birinci kat $X-X$ yönünde, $\% 93.5$, Birinci kat $Y-Y$ yönünde $\% 9.9$, İkinci kat $X-X$ yönünde $\% 91.7$, İkinci kat $Y-Y$ yönünde, \%9.9, Üçüncü kat $X-X$ yönünde $\% 67.2$, Üçüncü kat $Y-Y$ yönünde, $\% 0.8$, Dördüncü kat $X-X$ yönünde \%26.7, Dördüncü kat Y-Y yönünde, \%0.5, olarak elde edilmiştir.

2018 Türkiye Deprem Yönetmeliği’ne göre 5 katlı yığma binanın göçme durumunda olduğu belirlenmiştir. Analiz özeti Tablo 4'te verilmiştir. Analiz sonucunda tüm katların, basınç ve kayma gerilmelerini sağlamayan elemanlar Şekil 6-10'da verilmiştir. Şekillerde Turuncu renkli duvarlar; Basınç gerilmesini sağlamayan elemanları, Mor renkli duvarlar; Kayma gerilmesini sağlamayan elemanları ve Kırmızı renkli duvarlar ise Basınç ve kayma gerilmesini sağlamayan elemanları göstermektedir. 
Tablo 4. 5 Katlı Kargir Yapının Analiz Sonuçları

\begin{tabular}{|c|c|c|c|c|c|c|}
\hline$\overline{\text { Kat İsmi }}$ & Deprem Yönü & $\begin{array}{c}\mathbf{Q}_{\mathbf{i}} \\
(\text { ton })\end{array}$ & $\begin{array}{c}\mathbf{e} \\
(m)\end{array}$ & $\begin{array}{l}\mathbf{M}_{\mathbf{b i}} \\
(\mathrm{tm})\end{array}$ & $\begin{array}{l}\Sigma \mathbf{V}_{\mathbf{r}} \\
\text { (ton) }\end{array}$ & $\begin{array}{l}\Sigma \mathbf{V}_{\mathbf{a}} \\
\left(m^{2}\right)\end{array}$ \\
\hline \multirow{2}{*}{ Zemin Kat } & $\overline{X-X}$ & \multirow{2}{*}{84.4} & -1.04 & 20.5 & 230.66 & 6.02 \\
\hline & $Y-Y$ & & 0.24 & -87.42 & 382.88 & 7.65 \\
\hline \multirow{2}{*}{ 1. Kat } & $\mathrm{X}-\mathrm{X}$ & \multirow{2}{*}{79} & -1.03 & 19.92 & 205.66 & 6.02 \\
\hline & $Y-Y$ & & 0.25 & -81.04 & 332.66 & 7.65 \\
\hline \multirow{2}{*}{ 2. Kat } & $\mathrm{X}-\mathrm{X}$ & \multirow{2}{*}{68.17} & -1.03 & 17.18 & 180.58 & 6.02 \\
\hline & $Y-Y$ & & 0.25 & -69.92 & 282.67 & 7.65 \\
\hline \multirow{2}{*}{ 3. Kat } & $X-X$ & \multirow{2}{*}{51.92} & -1.03 & 13.09 & 155.51 & 6.02 \\
\hline & $Y-Y$ & & 0.25 & -53.25 & 232.87 & 7.65 \\
\hline \multirow{2}{*}{ 4. Kat } & $\mathrm{X}-\mathrm{X}$ & \multirow{2}{*}{30.25} & -1.03 & 7.63 & 130.43 & 6.02 \\
\hline & $Y-Y$ & & 0.25 & -31.03 & 183.22 & 7.65 \\
\hline$\overline{\text { Kat İsmi }}$ & Deprem Yönü & $\begin{array}{c}\Sigma \mathbf{V}_{\mathbf{n}} \\
(\text { Adet })\end{array}$ & $\begin{array}{c}\Sigma \text { Yetersiz } \mathbf{W}_{\mathbf{n}} \\
(\text { Adet }\end{array}$ & $\begin{array}{c}\text { Yetersiz } \Sigma \mathbf{V}_{\mathbf{r}} \\
\text { (ton) }\end{array}$ & $\begin{array}{c}\text { Yetersiz } \Sigma \mathbf{V}_{\mathbf{e}} \\
\text { (ton) }\end{array}$ & $\begin{array}{c}\text { Yetersiz } \Sigma \mathbf{V}_{\mathrm{e}} / \mathbf{Q}_{\mathbf{i}} \\
(\%)\end{array}$ \\
\hline \multirow{2}{*}{ Zemin Kat } & $\overline{X-X}$ & 22 & 10 & 148.98 & 79.26 & 93.9 \\
\hline & $Y-Y$ & 15 & 5 & 61.48 & 16.49 & 19.5 \\
\hline \multirow{2}{*}{ 1. Kat } & $\mathrm{X}-\mathrm{X}$ & 22 & 10 & 135.4 & 73.85 & 93.5 \\
\hline & $Y-Y$ & 15 & 3 & 20.47 & 7.85 & 9.9 \\
\hline \multirow{2}{*}{ 2. Kat } & $\mathrm{X}-\mathrm{X}$ & 22 & 8 & 111.53 & 62.48 & 91.7 \\
\hline & $Y-Y$ & 15 & 3 & 18.50 & 6.77 & 9.9 \\
\hline \multirow{2}{*}{ 3. Kat } & $\mathrm{X}-\mathrm{X}$ & 22 & 5 & 61.31 & 34.87 & 67.2 \\
\hline & $Y-Y$ & 15 & 2 & 1.4 & 0.41 & 0.8 \\
\hline \multirow{2}{*}{ 4. Kat } & $\mathrm{X}-\mathrm{X}$ & 22 & 1 & 8.41 & 8.09 & 26.7 \\
\hline & $Y-Y$ & 15 & 1 & 0.72 & 0.16 & 0.5 \\
\hline
\end{tabular}

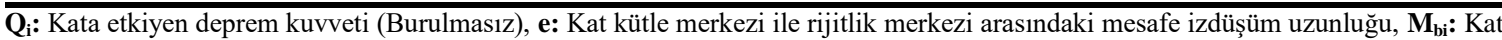
Burulma momenti, $\mathbf{\Sigma} \mathbf{V}_{\mathrm{r}}$ : Duvar kesme kuvvet taşıma kapasitesi, $\mathbf{\Sigma} \mathbf{V}_{\mathrm{e}}$ : Duvarlara etkiyen toplam kesme kuvveti (Burulma dahil), Yetersiz $\Sigma \mathbf{V}_{\mathbf{r}}$ : Kapasitesi yetersiz duvarların kesme kapasitesi toplamı, Yetersiz $\Sigma \mathbf{V}_{\mathbf{e}}$ : Kapasitesi yetersiz duvarlara gelen toplam kesme kuvveti (Burulma dahil), $\boldsymbol{\Sigma} \mathbf{W}_{\mathrm{a}}$ : Kattaki ilgili yönde duvar alanı bileşeni, $\boldsymbol{\Sigma} \mathbf{W}_{\mathbf{n}}$ : Kattaki ilgili yönde duvar sayısı, Yetersiz $\boldsymbol{\Sigma} \mathbf{V}_{\mathbf{n}}$ : Kesme kapasitesi yetersiz duvar sayıs.

\section{B. 5 KATLI KARGIR YAPININ DONATILI SIVA İLE GÜÇLENDİRİLMESI}

Performans Analizi yapılan binanın sonucu göçme durumunda çıkmıştır. Mevcut yapının iyileştirilmesi için taşıyıcı elemanlarda güçlendirme yapılarak, göçmenin önüne geçilebileceği düşünülmüş StatiCAD Yığma programında var olan hasır çelik donatılı sıva ile güçlendirme yöntemi aşağıdaki maddeler halinde sıralanan şartlar dikkate alınarak basınç ve kesme dayanımı yetersiz duvarların rijtliği ve kesme dayanımı arttırılması amaçlanmıştır. 2018 deprem yönetmeliğine uygun olarak, hasır çelik donatılı sıva ile güçlendirme yöntemi için uygulama şartları aşağıda maddeler halinde sıralanmıştır.

- Güçlendirme yapılacak sıva tabakası kalınlığı en az $30 \mathrm{~mm}$, hasır donatı paspayı en az $20 \mathrm{~mm}$ alınmalıdır. Sıvanın basınç dayanımı en az 5 Mpa olarak kabul edilmiştir.

- Güçlendirme yapılacak duvarların köşegen uzunluğunun güçlendirme öncesi kalınlığına oranı 30'dan küçük olmalıdır. Mevcut çerçeve içinde basınç çubuğu oluşumu sağlanmalı, yük aktarımı için ankrajlar düzenlenmelidir. Duvar yüzü ile çerçeve elemanlarının dış yüzü arasında en az $30 \mathrm{~mm}$ boşluk olmalıdır. Aksi halde güçlendirme uygulanamaz.

- Donatılı sıva tabakası ile çerçeve elemanları arasındaki ankraj çubuğunun en küçük çap1 12 $\mathrm{mm}$, en az derinliği çubuk çapının on katı ve en geniş çubuk aralığı $300 \mathrm{~mm}$ olmalıdır. Donatılı sıva ile mevcut duvarın beraber çalışması için duvar düzlemine dik, her bir metrekarede dört adet gövde ankrajı yapılmalıdır. Ankraj çubukları harç derzleri içinde kalmalı ve çubuk çapı en az $8 \mathrm{~mm}$, derinliği çubuk çapının en az on katı olmalıdır. Duvar düzlemine dik ve paralel yapılacak tüm ankrajlar açılacak deliklere epoksi esaslı bir malzeme ile ekilmeli, uçları $\mathrm{L}$ şeklinde 90 derece eğilerek hasır donatının içine geçirilmelidir.

- Q188/188 tipi 150x150 mm açıklığında $\phi 6{ }^{\prime}$ lık S420 donatı kullanılmalıdır.

- Oluşan kuvvetlerin zemine aktarılması için gerekli olan temel düzenlemesi yapılmalıdır. 
Binanın hasır çelik donatılı sıva yöntemi kullanılarak güçlendirilmiş cephe görüntüleri Şekil 5 'te verilmiştir.
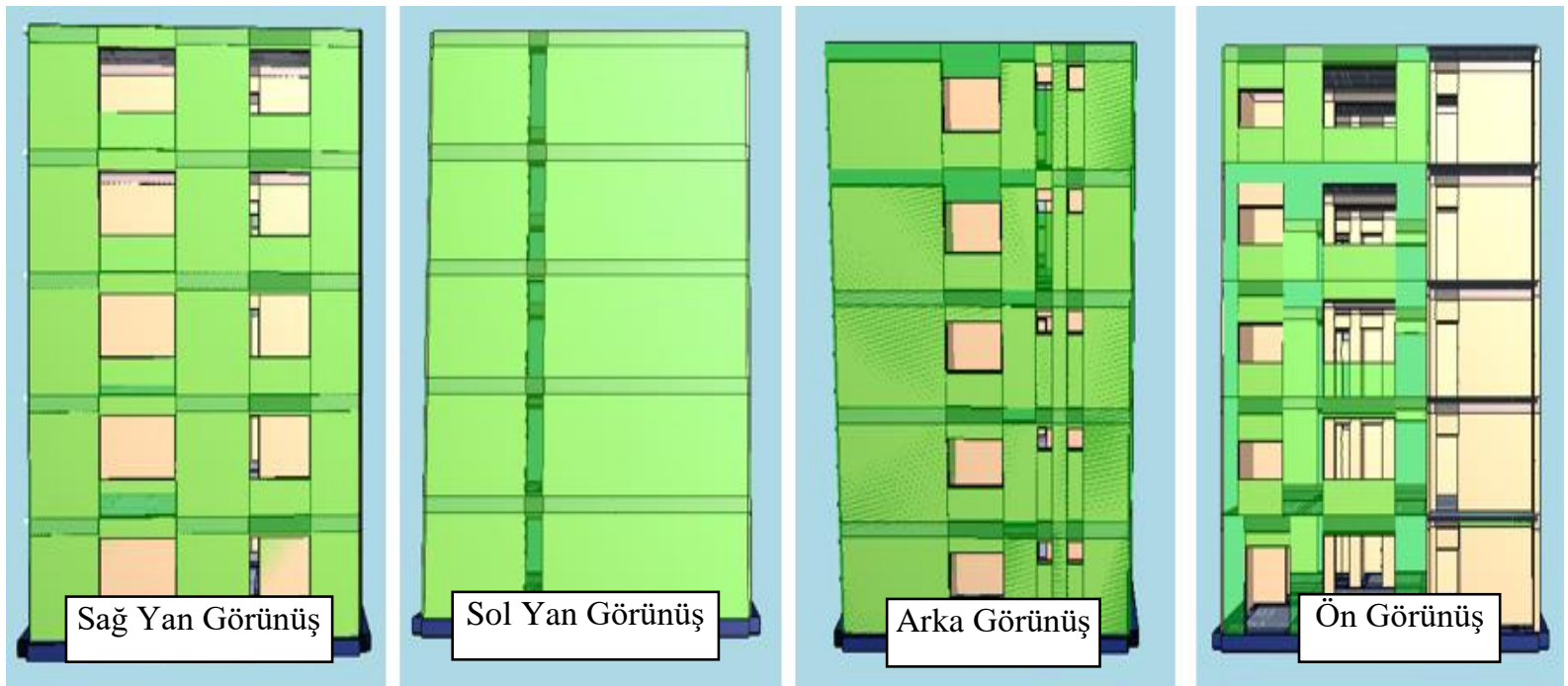

Şekil 5. 5 Katll Yığma Yapının Güçlendirme Sonrası Dört Cepheden Görüntüsü

Güçlendirme mevcut yapı da gözlenen basınç gerilmesini ve kayma gerilmesini sağlamayan elemanlar için yapılmıştır. Bina iç ve dış kısmında yapılan işlemler aşağıda verilmiştir.

$\checkmark$ Binanın dört cephesinde ve tüm katlara sadece dıştan $5 \mathrm{~cm}$ kalınlığında tek taraflı donatılı sıva güçlendirilmesi uygulanmıştır.

$\checkmark$ Bina iç kısmında bazı yapı elemanlarında basınç gerilmesini sağlamayan duvarları lokal olarak güçlendirme uygun görülmüștür. Bu kapsamda tüm katlarda $\mathrm{G}-\mathrm{G}$ aksında bulunan balkon penceresi kaldırılarak duvar eklenmiştir

$\checkmark$ Zemin katta, E-E aksında bulunana WZ14 nolu duvara, G-G aksında sonradan eklenen WZ16 nolu duvara $5 \mathrm{~cm}$ kalınlığında çift taraflı donatılı sıva güçlendirilmesi uygulanmıştır.

$\checkmark$ 1. katta, E-E aksında bulunana WZ14 nolu duvara, $5 \mathrm{~cm}$ kalınlığında çift taraflı donatılı sıva güçlendirilmesi uygulanmıştır.

$\checkmark$ Zemin ve 1. katta, 2-2 ve 4-4 akslarında bulunan tüm duvarlara $5 \mathrm{~cm}$ kalınlığında çift taraflı donatılı sıva güçlendirilmesi uygulanmıştır.

$\checkmark$ 2. Katta, E-E aksinda W214 nolu duvara, 2-2 aksinda W219, W220 ve W224 nolu duvarlara, 4-4 aksında W226 ve W227 nolu duvarlara $5 \mathrm{~cm}$ kalınlığında çift taraflı donatılı siva güçlendirilmesi uygulanmıştır.

$\checkmark$ 3. Katta, 2-2 aksinda W319, W320 ve W324 nolu duvarlara, 4-4 aksinda W326 ve W327 nolu duvarlara $5 \mathrm{~cm}$ kalınlığında çift taraflı donatılı sıva güçlendirilmesi uygulanmıştır.

Güçlendirme sonucu yapılan analiz sonuçları Tablo 5'te verilmiştir. Güçlendirme öncesi basınç ve kayma gerilmeleri açısından yetersiz tüm katlarda 48 adet duvar, güçlendirme sonucu yeterli hale gelmiştir. Güçlendirme öncesi ve sonrası tüm katlara ait analiz sonuçları şekil 6-10'da karşılaştırmalı olarak verilmiştir. 
Tablo 5. 5 Katlı Yığma Binanın Güçlendirme Sonrası Analiz Sonuçları

\begin{tabular}{|c|c|c|c|c|c|c|}
\hline$\overline{\text { Kat İsmi }}$ & Deprem Yönü & $\begin{array}{c}\mathbf{Q}_{\mathbf{i}} \\
\text { (ton) }\end{array}$ & $\begin{array}{c}\mathbf{e} \\
(m)\end{array}$ & $\begin{array}{l}\mathbf{M}_{\mathbf{b i}} \\
(\mathrm{tm})\end{array}$ & $\begin{array}{l}\Sigma \mathbf{V}_{\mathbf{r}} \\
\text { (ton) }\end{array}$ & $\begin{array}{l}\Sigma \mathbf{V}_{\mathbf{a}} \\
\left(m^{2}\right)\end{array}$ \\
\hline \multirow{2}{*}{ Zemin Kat } & $\overline{X-X}$ & \multirow{2}{*}{95.58} & -0.95 & -60.89 & 265.29 & 6.08 \\
\hline & $Y-Y$ & & -0.64 & -90.98 & 443.85 & 7.59 \\
\hline \multirow{2}{*}{ 1. Kat } & $\mathrm{X}-\mathrm{X}$ & \multirow{2}{*}{89.07} & -0.89 & -88.77 & 243.53 & 6.08 \\
\hline & $\mathrm{Y}-\mathrm{Y}$ & & -1 & -79.26 & 384.6 & 7.59 \\
\hline \multirow{2}{*}{ 2. Kat } & $\mathrm{X}-\mathrm{X}$ & \multirow{2}{*}{76.18} & -1.37 & -174.39 & 215.56 & 6.08 \\
\hline & $Y-Y$ & & -2.29 & -104.22 & 328.77 & 7.59 \\
\hline \multirow{2}{*}{ 3. Kat } & $\mathrm{X}-\mathrm{X}$ & \multirow{2}{*}{57.6} & -1.42 & -181.68 & 188.49 & 6.08 \\
\hline & $\mathrm{Y}-\mathrm{Y}$ & & -3.15 & -81.59 & 272.94 & 7.59 \\
\hline \multirow{2}{*}{ 4. Kat } & $\mathrm{X}-\mathrm{X}$ & \multirow{2}{*}{33.09} & -2.26 & -108.24 & 161.45 & 6.08 \\
\hline & $\mathrm{Y}-\mathrm{Y}$ & & -3.27 & -74.71 & 220.14 & 7.59 \\
\hline Kat İsmi & Deprem Yönü & $\begin{array}{c}\Sigma \mathbf{V}_{\mathbf{n}} \\
(\text { Adet })\end{array}$ & $\begin{array}{c}\Sigma \text { Yetersiz } \mathbf{W}_{\mathbf{n}} \\
(\text { Adet })\end{array}$ & $\begin{array}{c}\text { Yetersiz } \Sigma \mathbf{V}_{\mathbf{r}} \\
\text { (ton) })\end{array}$ & $\begin{array}{c}\text { Yetersiz } \Sigma \mathbf{V}_{\mathbf{e}} \\
(\text { ton })\end{array}$ & $\underset{(\%)}{\text { Yetersiz } \Sigma \mathbf{V}_{\mathrm{e}} / \mathbf{Q}_{\mathbf{i}}}$ \\
\hline \multirow{2}{*}{ Zemin Kat } & $\mathrm{X}-\mathrm{X}$ & 21 & 0 & 0 & 0 & 0 \\
\hline & $\mathrm{Y}-\mathrm{Y}$ & 13 & 0 & 0 & 0 & 0 \\
\hline \multirow{2}{*}{ 1. Kat } & $\mathrm{X}-\mathrm{X}$ & 20 & 0 & 0 & 0 & 0 \\
\hline & $\mathrm{Y}-\mathrm{Y}$ & 13 & 0 & 0 & 0 & 0 \\
\hline \multirow{2}{*}{ 2. Kat } & $\mathrm{X}-\mathrm{X}$ & 20 & 0 & 0 & 0 & 0 \\
\hline & $Y-Y$ & 13 & 0 & 0 & 0 & 0 \\
\hline \multirow{2}{*}{ 3. Kat } & $\mathrm{X}-\mathrm{X}$ & 20 & 0 & 0 & 0 & 0 \\
\hline & $Y-Y$ & 13 & 0 & 0 & 0 & 0 \\
\hline \multirow{2}{*}{ 4. Kat } & $X-X$ & 20 & 0 & 0 & 0 & 0 \\
\hline & $Y-Y$ & 13 & 0 & 0 & 0 & 0 \\
\hline
\end{tabular}

Q $\mathbf{Q}_{\mathbf{i}}$ : Kata etkiyen deprem kuvveti (Burulmasız), e: Kat kütle merkezi ile rijitlik merkezi arasındaki mesafe izdüşüm uzunluğu, $\mathbf{M}_{\mathrm{bi}}$ : Kat Burulma momenti, $\boldsymbol{\Sigma} \mathbf{V}_{\mathrm{r}}$ : Duvar kesme kuvvet taşıma kapasitesi, $\boldsymbol{\Sigma} \mathbf{V}_{\mathrm{e}}$ : Duvarlara etkiyen toplam kesme kuvveti (Burulma dahil), Yetersiz $\Sigma \mathbf{V}_{\mathbf{r}}$ : Kapasitesi yetersiz duvarların kesme kapasitesi toplamı, Yetersiz $\boldsymbol{\Sigma} \mathbf{V}_{\mathrm{e}}$ : Kapasitesi yetersiz duvarlara gelen toplam kesme kuvveti (Burulma dahil), $\mathbf{\Sigma} \mathbf{W}_{\mathbf{a}}$ : Kattaki ilgili yönde duvar alanı bileşeni, $\boldsymbol{\Sigma}_{\mathbf{n}}$ : Kattaki ilgili yönde duvar sayıs1, Yetersiz $\Sigma \mathbf{V}_{\mathbf{n}}$ : Kesme kapasitesi yetersiz duvar sayısı.
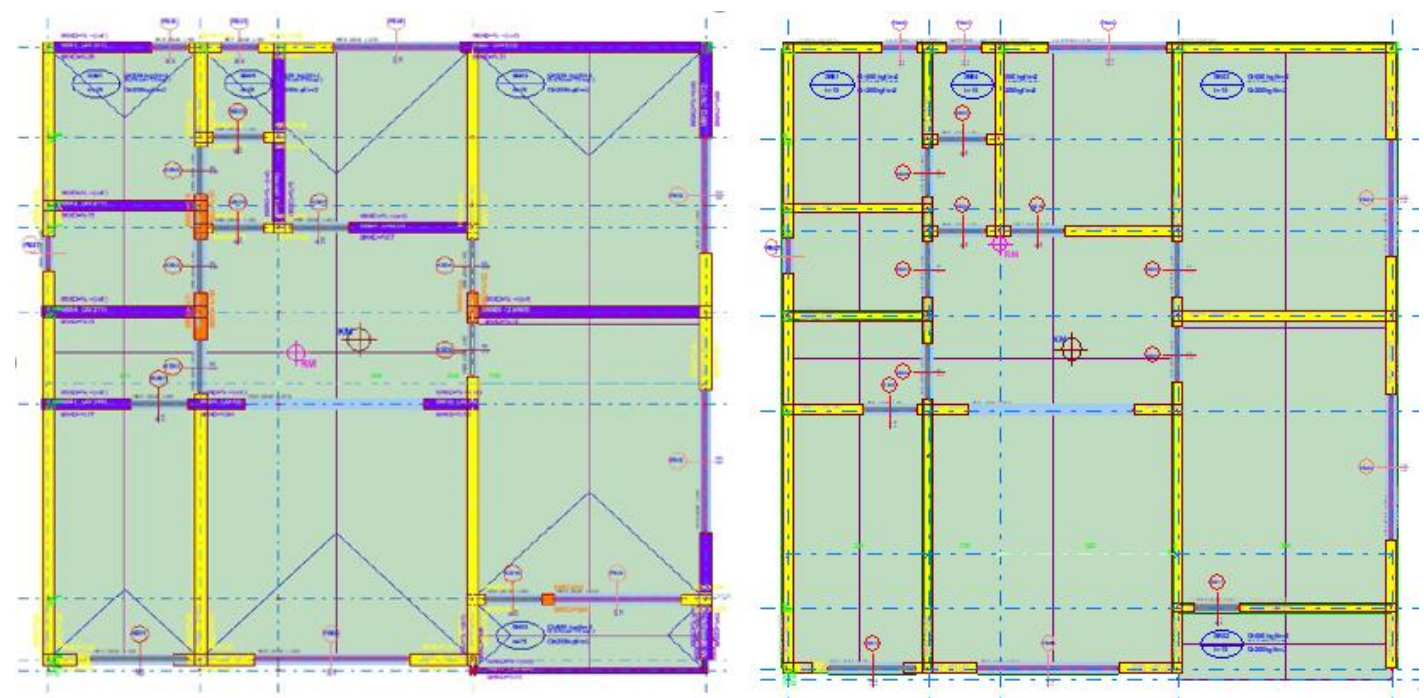

Şekil 6. Zemin kat planı güçlendirme öncesi ve sonrası analiz sonucu 

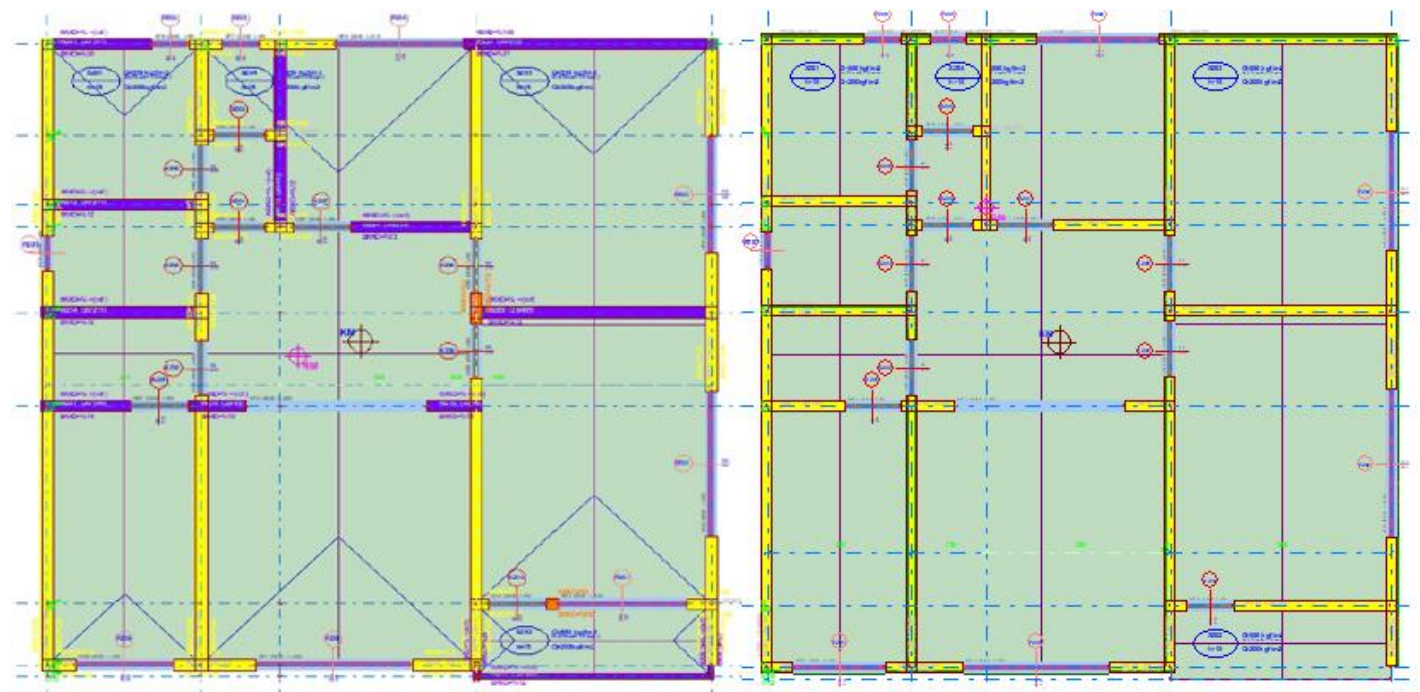

Şekil 7. 1. kat planı güçlendirme öncesi ve sonrası analiz sonucu
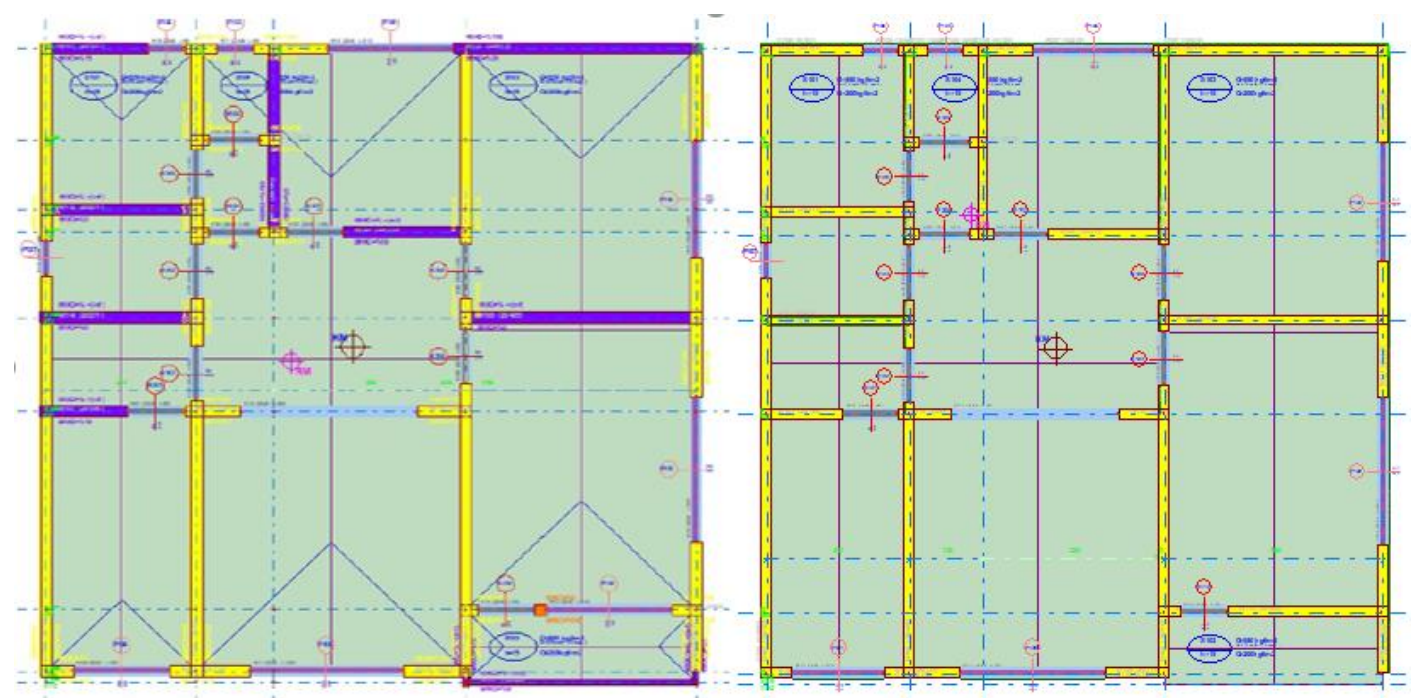

Şekil 8. 2. kat planı güçlendirme öncesi ve sonrası analiz sonucu
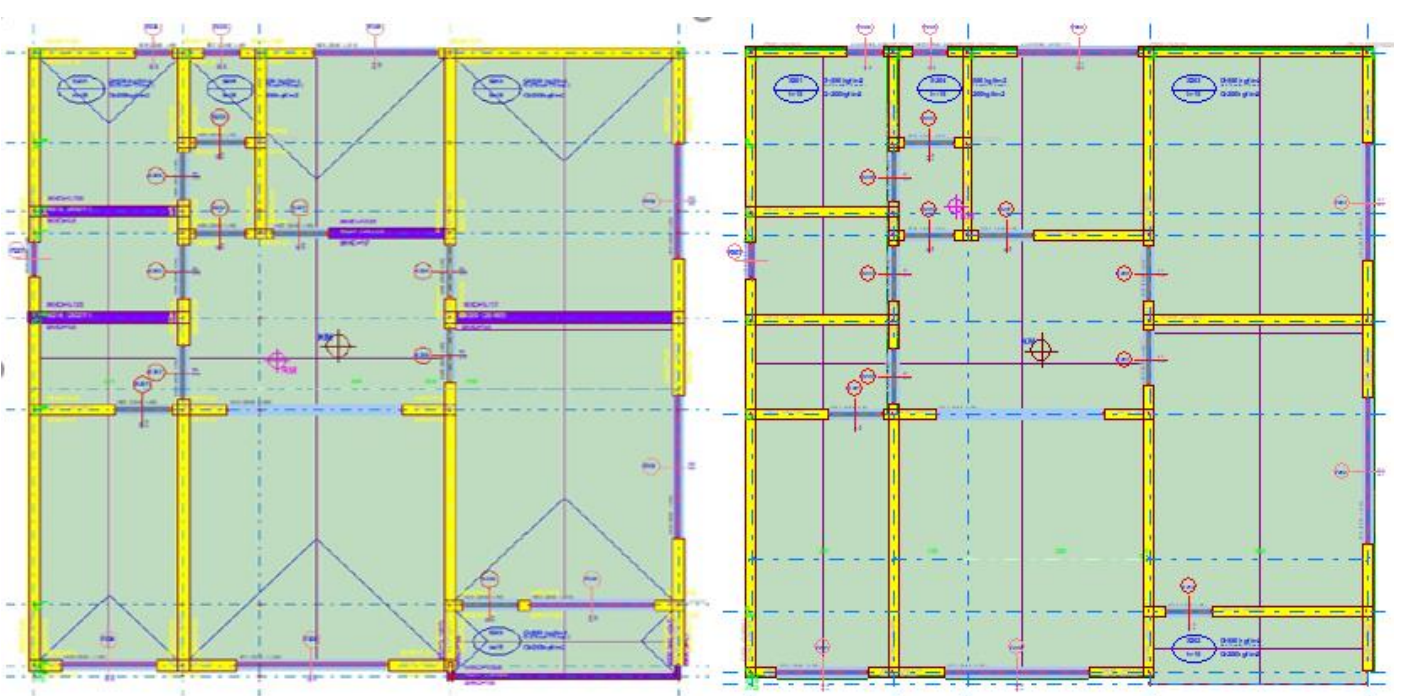

Şekil 9. 3. kat planı güçlendirme öncesi ve sonrası analiz sonucu 

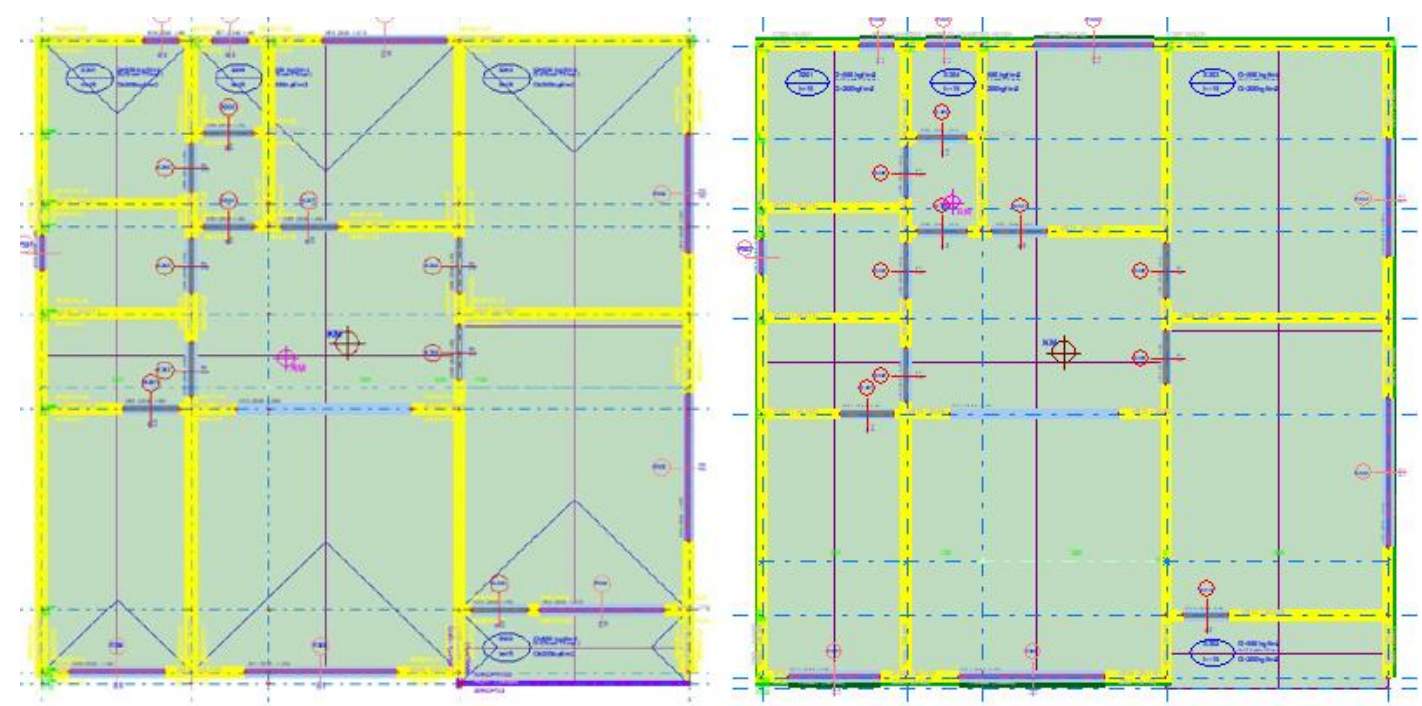

Şekil 10. 4. kat planı güçlendirme öncesi ve sonrası analiz sonucu

\section{SONUC}

$\mathrm{Bu}$ çalışmada StatiCAD Yığma programı kullanılarak 5 Katlı yığma binanın, 2018 Deprem Yönetmeliğine göre 50 yılda gerçekleşme ihtimali \%10 olan depremler dikkate alınarak performans analizi yapılmıştır. Analizde kullanılmış olan yapı malzemesinin mekanik özellikleri literatürdeki benzer çalışmalardan referans alınmıştır. Harman tuğlası ve harcın tek bir malzeme gibi modellenmesinden dolayı analiz sonuçları kaba bir yaklaşımla elde edilmiştir. Bina her katta aynı plana sahiptir. Her kat 37 duvardan oluşmaktadır. Analiz sonucunda Zemin katta 15, 1. Katta 13, 2. Katta 11, 3. Katta 7, ve 4. Katta 2 duvar olmak üzere binada toplamda 48 duvar basinç ve kayma gerilmesi açısından yetersiz çıkmıştır. 2018 Deprem Yönetmeliğine göre binanın bulunduğu bölge dikkate alınarak hazırlanan davranış spektrumu verilerine göre hesap yapıldığında yapıda mevcut duvarların taşıma kapasitesi, binada oluşan basınç ve kayma gerilmelerine karşı yetersiz kaldığından, yapılan analiz sonucu göçme durumunda çıkmıştır. Güçlendirme öncesi bina toplam kütlesi 745.87 ton iken, güçlendirme sonrası yaklaşık \%13 artarak 844.68 ton olmuştur. Bölüm 3.2'de belirtildiği gibi yapılan güçlendirme sonrası; tüm duvarlar basınç ve kayma gerilmesi açısından yeterli hale gelmiştir. Güçlendirme sonrası yapılan analiz sonucunda bina emniyet gerilmeleri değerlerini sağladığı yani hemen kullanım durumunda olduğu sonucuna ulaşılmıştır.

Yığma yapıları sadece tarihi mekânlar olarak veya az katlı binalar olarak değerlendirmemek gerekir. $\mathrm{Bu}$ çalışma ülkemizde konut olarak kullanılan mühendislik hizmeti almış çok katlı yığma binaları temsilen, deprem performans analizi yapılması ve gerekirse güçlendirme önerilerinde bulunmak açısından iyi örnek olarak gösterilebilir.

TEȘEKKÜR: Veysel AKBAŞ'a binasına ait bilgileri / verileri araştırmamızda kullanmamıza izin verdiği için teşekkür ederim.

\section{KAYNAKLAR}

[1] İ. İ. Atabey, "Yığma binaların performans analizi Sivas Suşehri Aşağısarıca İlköğretim Okulu örneği,” Yüksek Lisans tezi, Yapı Eğitimi, Gazi Üniversitesi, Ankara, Türkiye, 2011.

O. A. Düzgün, Y. S. Hatipoğlu, M. Artar, M. Yurdakul, ve E. Öner, “Zahit Efendi Camisi’nin 
sonlu elemanlar analizi," 5. Tarihi Eserlerin Güçlendirilmesi ve Geleceğe Güvenle Devredilmesi Sетроzуити, Erzurum, Türkiye, 2015, ss.155-168.

[3] Türkiye İstatistik Kurumu, Bina Sayımı 2000, Ankara, Türkiye: Devlet İstatistik Enstitüsü Matbaas1, 2001.

[4] A. Batur, "Donatısız yığma binaların yatay yükler altındaki davranışı ve bazı ülkelerin şartnamelerinin incelenmesi," Yüksek Lisans tezi, İnşaat Mühendisliği Bölümü, İstanbul teknik Üniversitesi, İstanbul, Türkiye, 1999.

[5] A İ. Ünay, Tarihi Yapıların Depreme Dayanımı., 1. baskı, Ankara, Türkiye: O.D.T.Ü Yayınevi, 2002.

[6] İ. Kılıç, H. Coşkun, ve H. Uslu, "Hatay Hükümet Konağı'nın deprem yükleri etkisinde davranışının incelenmesi," 2. Türkiye Deprem Mühendisliği ve Sismoloji Konferansı, Hatay, Türkiye, 2013, ss. 1-8.

[7] Ö. Dabanlı, "Tarihi yığma yapıların deprem performansının belirlenmesi," Yüksek Lisans tezi, İnşaat Mühendisliği Bölümü, Yıldız Teknik Üniversitesi, İstanbul, Türkiye, 2008.

[8] E. Sayın, "Yığma yapıların lineer olmayan statik ve dinamik analizi," Doktora tezi, İnşaat Mühendisliği Bölümü, Fırat Üniversitesi, Elazığg, Türkiye, 2009.

[9] R. Y. Chamaky, "Tarihi yığma yapıların deprem analizi ve uygun güçlendirme teknikleri," Yüksek Lisans tezi, İnşaat Mühendisliği Bölümü, Yıldız Teknik Üniversitesi, İ̀stanbul, Türkiye 2014.

[10] F. Aköz ve N. Yüzer, "Tarihi yapılarda malzeme özelliklerinin belirlenmesinde uygulanan yöntemler” IMO-1. Insaat Muhendisligi Egitimi Sempozyumu, Antalya, Türkiye, 2009, ss. 6-7.

[11] A. H. Aköz, "Deprem etkisi altındaki tarihi yığma yapıların onarım ve güçlendirilmesi," Yüksek Lisans tezi, İnşaat Mühendisliği Bölümü, İstanbul Teknik Üniversitesi, İstanbul, Türkiye 2008.

[12] G. Çal ve A. Şahin, “Ortaköy Büyük Mecidiye Camii’nin farklı deprem etkileri altında sismik davranışının değerlendirilmesi” 5. Tarihi Eserlerin Güçlendirilmesi ve Geleceğe Güvenle Devredilmesi Sempozyumu, Erzurum, Türkiye, 2015, ss. 1-10.

[13] Ö. Can ve H. Yıldızoğlu, "Yığma binalarda deprem performansının belirlenmesi (Bayburt Korkut Ata Lisesi örneği)," Gümüşhane Üniversitesi Fen Bilimleri Enstitüsü Dergisi, c. 8, s. 2, ss. 372-380, 2018.

[14] Ö. Can ve B. Erkul, "Ahşap döşemeli geleneksel Bayburt evinin deprem performansının belirlenmesi,” Düzce Üniversitesi Bilim ve Teknoloji Dergisi, c. 7, s. 1, ss. 369-382, 2019.

[15] M. Uzun, "Yığma yapıların deprem performansının değerlendirilmesi ve bir güçlendirme örneği,” Yüksek Lisans tezi, İnşaat Mühendisliği Bölümü, Selçuk Üniversitesi, Konya, Türkiye, 2017.

[16] O. Cenik, H. H. Selim, ve K. Güler, "Kadıköy (İstanbul)'de yığma bir binanın deprem riskinin belirlenmesi," Uygulamalı Yerbilimleri Dergisi, c. 17, s. 1, ss. 69-85, 2018.

[17] H. Can ve A. İ. Ünay, "Tarihi yapıların deprem davranışını belirlemek için sayısal analiz yöntemleri," Gazi Üniversitesi Mühendislik ve Mimarlık Fakültesi Dergisi, c. 1, s. 27, ss. 211-217, 2012.

[18] A. B. Çobanoğlu, "Türkiye'deki yığma binaların malzeme özelliklerinin incelenmesi," Yüksek 
Lisans tezi, İnşaat Mühendisliği Bölümü, Ortadoğu Teknik Üniversitesi, Ankara, Türkiye, 2014.

[19] A. Arslan, "Süleymaniye Camii'nin yerel zemin koşullarına bağlı deprem performansının değerlendirilmesi," Yüksek Lisans tezi, İnşaat Mühendisliği Bölümü, Yıldız Teknik Üniversitesi, 2016.

[20] T.C. İç İşleri Bakanlığı Afet ve Acil Durum Başkanlığı, Resmi Gazete sayı: 30364. (2018, 18 Mart), Türkiye Bina Deprem Yönetmeliği. [Çevrimiçi]. Erişim: https://www.resmigazete.gov.tr/eskiler/2018/03/20180318M1-2.htm

[21] A. Ural, "Yığma yapıların doğrusal ve doğrusal olmayan davranışlarının incelenmesi," Doktora tezi, İnşaat Mühendisliği Bölümü, Karadeniz Teknik Üniversitesi, Trabzon, Türkiye, 2009.

[22] Betonarme Yapıların Tasarım ve Yapım Kuralları, Türk Standartları Entitüsü, TS 500, 2000. 